\title{
A new accelerated technique for validation of cyclic plasticity models
}

\author{
Radim Halama ${ }^{1,2, *}$, Petr Gál ${ }^{2,3}$, Zbyněk Paška ${ }^{2}$, Josef Sedlák ${ }^{2}$ \\ ${ }^{1}$ IT4Innovations, VŠB - Technical University of Ostrava, 17. listopadu 2172/15, 70833 Ostrava- \\ Poruba, Czech Republic \\ ${ }^{2}$ Faculty of Mechanical Engineering, VŠB - Technical University of Ostrava, 17. listopadu 2172/15, \\ 70833 Ostrava-Poruba, Czech Republic \\ ${ }^{3}$ Integrity and Technical Engineering Division, Újv Řež a. s., Hlavní 130, 25068 Husinec - Řež, \\ Czech Republic
}

\begin{abstract}
This contribution presents a new methodology of fatigue tests evaluation based on digital image correlation application. The full-field strain analysis brings the possibility of 3D strain measurement evaluation on a curved part of specimen standardly used under axial-torsional loading. Resulting strain response curves can subsequently serve for evaluation of cyclic plasticity model predictions. The crucial idea is the way of FE model creation to can evaluate simulation in the same points of the structure as in the DIC measurement. The new methodology saves amount of material and leads to a shorter experimental time.
\end{abstract}

Keywords: digital image correlation, ratcheting, cyclic plasticity, fatigue testing

\section{Introduction}

Accurate cyclic plasticity modelling based on phenomenological approach requires numerous experimental results. Extensive low-cycle fatigue testing of metallic materials brings knowledge about suitability of individual approach [1]. Transient stress/strain behaviour of metals have been identified for various effects of cyclic plasticity, considering cyclic hardening/softening mechanisms, for instance in cyclic creep (or so called ratcheting) and mean stress relaxation [2]. Additional hardening due to non-proportional loading is also a complicated factor. It is not surprising, that researchers have been looking for new testing procedures to obtain more information for calibration of cyclic plasticity models in order to accelerate the whole process [3]. Recently, specimen's geometry is usually designed by means of finite element analyses support [4-5].

Cyclic plasticity models available in commercial software are usually not enough accurate for non-proportional loading cases [6]. On the other hand, the proportional loading cases, the Neuber like methods based on elastic solution are more efficient making possible the propabilistic approach [7].

This contribution follows previous research presented elsewhere [8]. The new approach of fatigue test evaluation is based on digital image correlation method application and

\footnotetext{
* Corresponding author: radim.halama@vsb.cz

Reviewers: Grzegorz Domek, Milan Sága
} 
brings a lot of new possibilities in mechanical testing of materials. All described cases deals with ratcheting under proportional loading, but the technique proposed here might be applied also for various cases of non-proportional loading to study stress-strain behaviour of materials more effectively.

\section{Experiments}

\subsection{Description}

All tests were realized on axial-torsional testing machine LabControl $100 \mathrm{kN} / 1000 \mathrm{Nm}$ at the VŠB -TU Ostrava [8]. In this study, uniaxial cases results are presented only. Digital image correlation (DIC) measurements were done via the Mercury RT® system (2x2.3Mpx@40Hz), provided by Sobriety s.r.o. company. An optical contrast coating was prepared on each specimen for DIC method application. The frequency of triangular loading was $0.1 \mathrm{~Hz}$ during DIC measurement in each test. Tubular specimens made of R7T wheel steel were made according to scheme in the Fig.1. The testing part had outer diameter $12.5 \mathrm{~mm}$ and inner diameter $10 \mathrm{~mm}$ respectively.

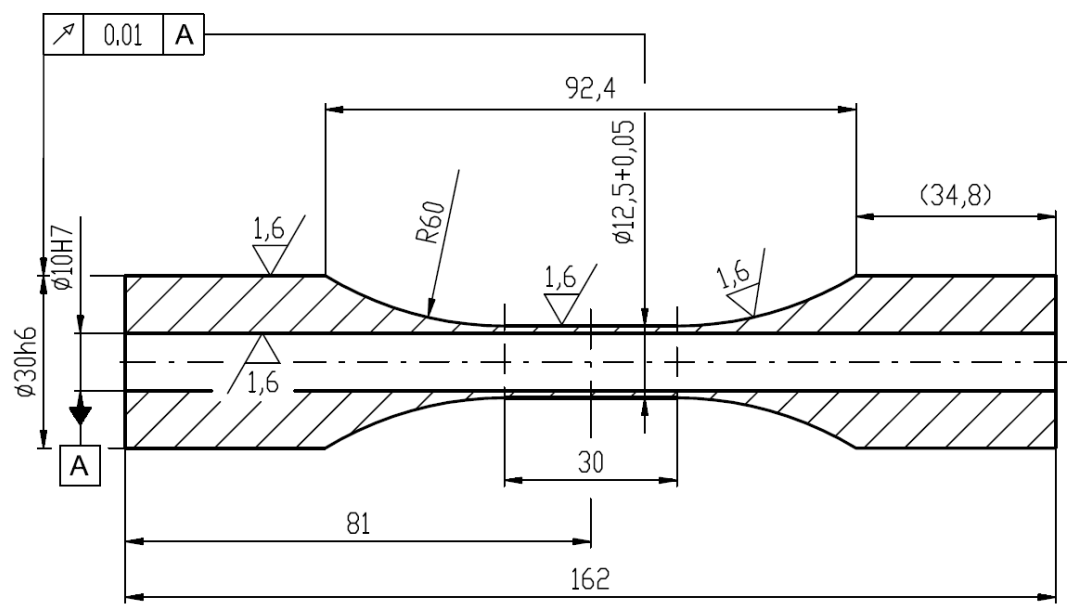

Fig. 1. A scheme of used specimen

\subsection{Results of strain controlled test}

A sequential test was performed under strain control to obtain the cyclic stress-strain curve of the R7T material. The monotonic stress-strain curve together with evaluated hysteresis loops is shown in the Fig. 2. A cyclic softening was observed for small strain amplitudes. A slight cyclic hardening for higher strain amplitudes is also visible.

\subsection{Results of stress controlled test}

The next realized experiment was intended to study uniaxial ratcheting of R7T steel [8]. A harmonic loading with the stress amplitude of $450 \mathrm{MPa}$ and mean stress of $50 \mathrm{MPa}$ was applied (the loading frequency was increased to $0.5 \mathrm{~Hz}$ after 200 cycles). The test was done until fracture. The material reveals a ratcheting behaviour with steady state after 
stabilization of strain response, see Fig. 3, where DIC measurement results are also depicted.



Fig. 2. Uniaxial hysteresis loops of investigated material gained from the sequential uniaxial test

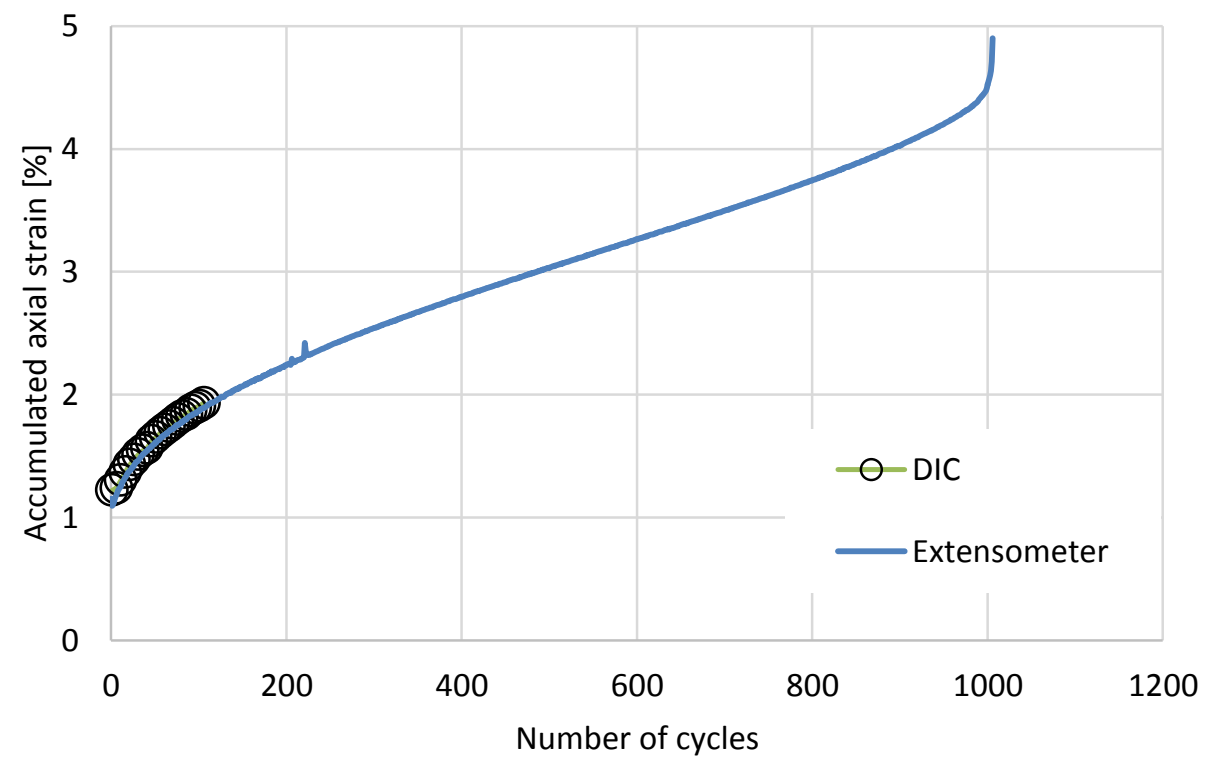

Fig. 3. Accumulation of axial strain in the uniaxial ratcheting test

Strain history was evaluated from DIC measurement in selected points as shown in the Fig. 4. The point A lies on the testing part of the specimen. The other points correspond to the curved part. The larger cross-section the less axial strain accumulation. The same behaviour was observed in realized measurement as will be presented in the next chapter. 


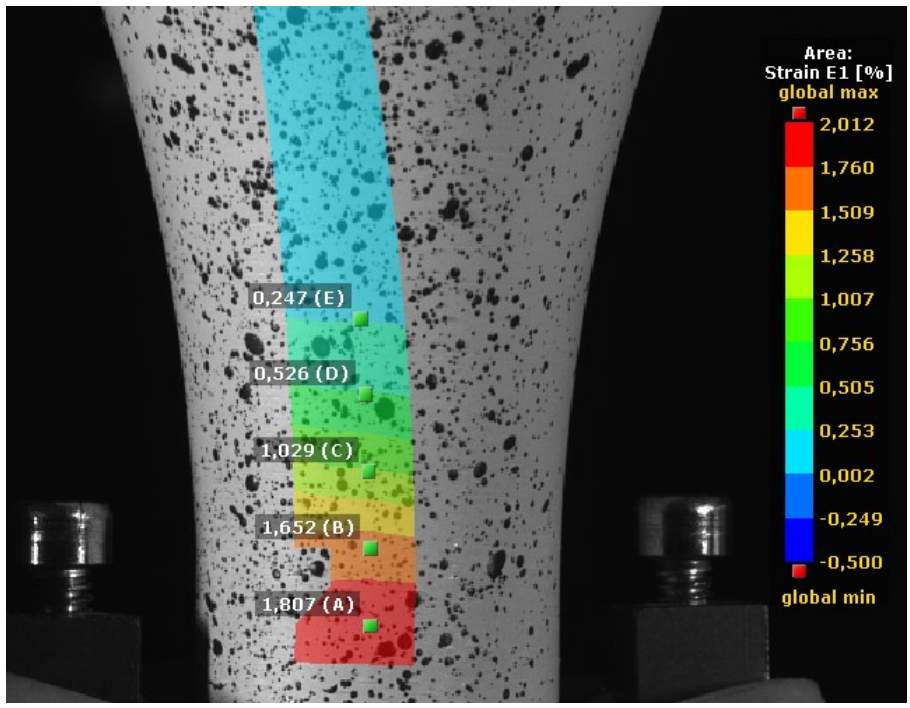

Fig. 4. First principal strain contours and points selected for evaluation of DIC measurement

Position of selected DIC points can be identified based on idea of approximation by circle with known radius (radius $R=60 \mathrm{~mm}$ ), see Fig. 5. Coordinates of points were gained using pixel coordinates and a scale factor calculated from ratio between diameter of testing part in $\mathrm{mm}$ and pixels. The approximation function is

$$
y=y_{0}+\sqrt{R^{2}-\left(x-x_{0}\right)^{2}},
$$

where $x_{0}$ and $y_{0}$ defines the centre of the approximation circle. The most important parameter for FE model creation is $x_{0}$. Its resulting value is $x_{0}=1.75 \mathrm{~mm}$.

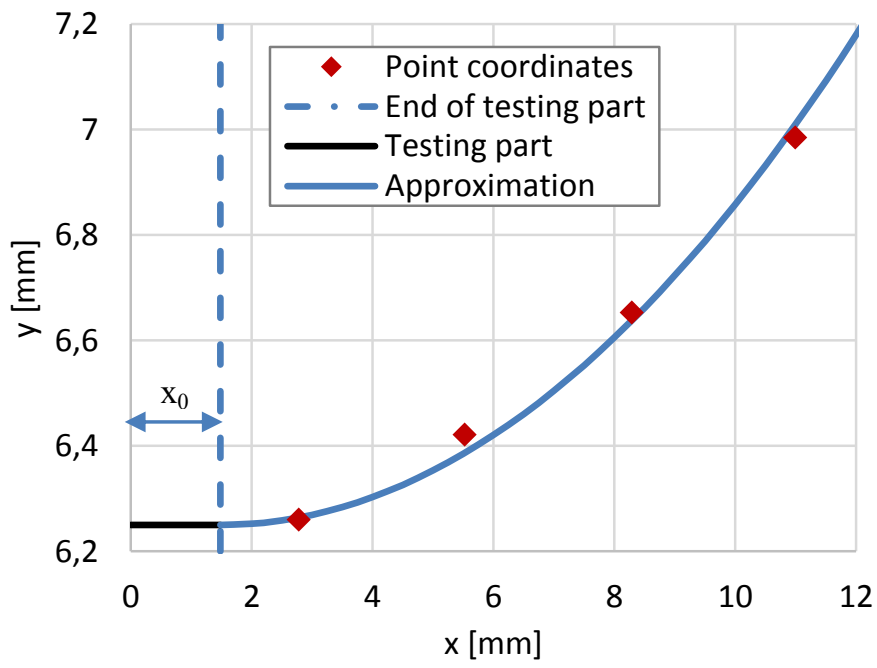

Fig. 5. Approximation of points evaluated from DIC measurement 


\section{Finite element modelling}

\subsection{FE model}

Commercial FE software ANSYS was used for the simulation of uniaxial ratcheting test. For simplicity, the axisymmetric model corresponding to the half of specimen was created (Fig. 6). The model consists of 204 elements (4 node structural 2D element, PLANE182). The model was prepared by APDL macro (Ansys Parametric Design Language) to can parametrically specify position of nodes accordingly the DIC measurement evaluation (points A-E). Boundary conditions shown in the Fig. 6 were applied. An overload in first loading cycle was also set as in actual experiment [8].



Fig. 6. FE model considered in the simulation

\subsection{Material model description}

A classic cyclic plasticity model with pure kinematic hardening was employed. The rateindependent cyclic plasticity theory considered in the ratcheting analysis consists of von Mises yield criterion

$$
f=\sqrt{\frac{3}{2}(\mathbf{s}-\mathbf{a}):(\mathbf{s}-\mathbf{a})}-\sigma_{Y}=0
$$

the associative flow rule

$$
d \boldsymbol{\varepsilon}_{p}=d \lambda \frac{\partial f}{\partial \boldsymbol{\sigma}}
$$


and the Chaboche kinematic hardening rule [9]

$$
\boldsymbol{a}=\sum_{i=1}^{M} \boldsymbol{a}_{i}, d \boldsymbol{a}_{i}=\frac{2}{3} C_{i} d \boldsymbol{\varepsilon}_{p}-\gamma_{i} \boldsymbol{a}_{i} d p,
$$

where $\boldsymbol{s}$ is the deviatoric part of stress tensor $\boldsymbol{\sigma}, \boldsymbol{a}$ is the deviatoric part of back-stress $\boldsymbol{\alpha}, \sigma_{Y}$ is the initial size of the yield surface, $d \lambda$ is the plastic multiplier, which in associative plasticity corresponds to the equivalent plastic strain increment $d p$, and $d \varepsilon_{\mathrm{p}}$ is the plastic strain tensor. The symbol ":" means the inner product between two second order tensors

$$
\mathbf{x}: \mathbf{y}=x_{i j} y_{i j}
$$

Yield stress $\sigma_{Y}$ and material parameters $C_{i}$ and $\gamma_{i}$ of $i$-th back stress part $\boldsymbol{a}_{i}$ were identified from the largest hysteresis loop shown in the Fig. 2. The parameter $\gamma_{3}$ influencing ratcheting rate was set to 0.65 to predict ratcheting rate in testing part of the specimen correctly. All material parameters used in the FE simulation is stated in the Table 1. These elastic constants were also used in the FEA: Young modulus $E=202000 \mathrm{MPa}$, Poisson's ratio $v=0.3$.

Table 1. Parameters of cyclic plasticity model

\begin{tabular}{|c|c|}
\hline Model & Parameters \\
\hline & $\sigma_{Y}=200 M P a$ \\
Chaboche & $C_{1-3}=243100,29370,8479 \mathrm{MPa}$ \\
& $\gamma_{1-3}=1423,213,0.65$ \\
\hline
\end{tabular}

\subsection{Results}

In total, 250 cycles was simulated. Contours of axial stress at the time corresponding to the first tension peak are shown in the Fig. 7, where evaluated nodes are also numbered.

The trend of ratcheting rate is predicted well for all cases. The best prediction in initial cycles was obtained for point $\mathrm{C}$ (node 132). For points $\mathrm{A}$ and $\mathrm{B}$ less ratcheting rate was obtained in initial cycles than in the experiment. In remaining points a strong overprediction of strain accumulation was obtained by the Chaboche model.

Complete stress-strain history was evaluated in the five nodes. It was checked that the same value of fatigue asymmetry factor $R=-0.8$ was obtained in the evaluated surface nodes. An example of stress-strain prediction is visible in the Fig. 8. Very slight change of stress amplitude occurs in initial cycles only. 

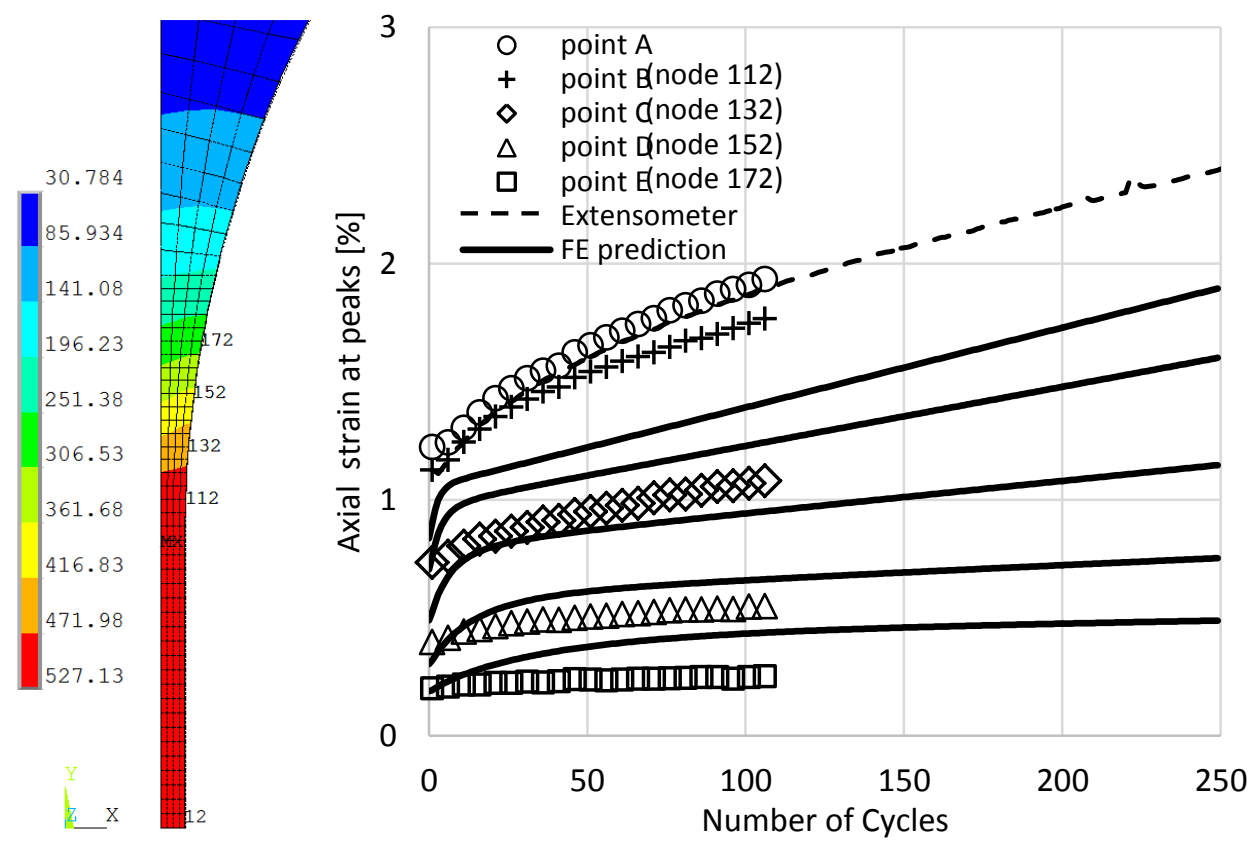

Fig. 7. Axial stress contours and resulting prediction of strain accumulation in comparison with values measured by DICM

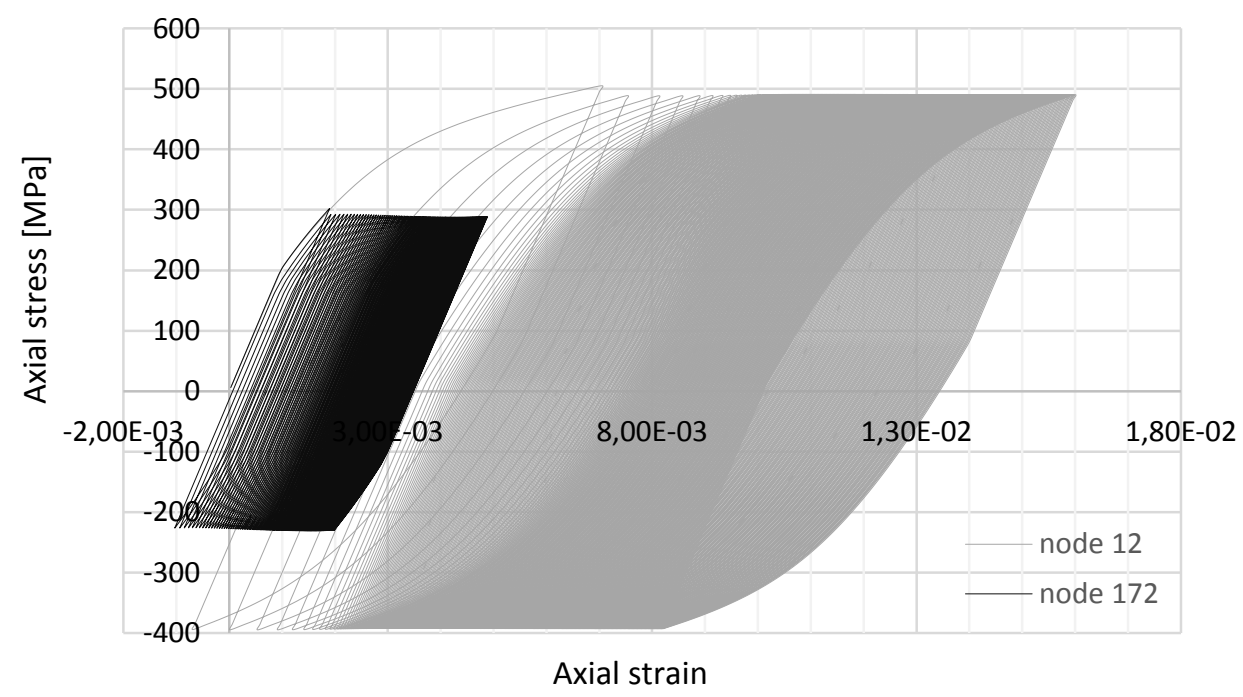

Fig. 8. Predicted hysteresis loops for node 12 and node 172

\section{Conclusion}

A new approach for low-cycle fatigue tests evaluation has been presented in this paper. Modern optical methods of full-field strain analysis make possible to get more information about stress-strain behaviour of the investigated material subjected to cyclic load. The proposed technique was validated using digital image correlation method. A possibility of 
FE model creation was also described. The technique can help researches to save time and number of specimens. Good correlation between FE prediction and experiments was obtained in steady state. Better results of ratcheting prediction can be obtained for instance by application of a new constitutive model including memory surface based on the AbdelKarim-Ohno kinematic hardening rule [10]. The numerical study will be presented in a future paper.

The digital image correlation technique application brings new possibility of transient material behaviour investigation not only for the case of ratcheting, but also in research of mean stress relaxation, cyclic hardening/softening, additional hardening due to nonproportional loading or in creep testing (optically screenable cases only).

This work was supported by The Ministry of Education, Youth and Sports from the National Programme of Sustainability (NPU II) project „IT4Innovations excellence in science - LQ1602“, by the Czech Science Foundation (GA15-18274S) and by the Specific Research (SP2017/136). The support is gratefully acknowledged.

\section{References}

1. R. Halama, J. Sedlák and M. Šofer, Phenomenological Modelling of Cyclic Plasticity, Chapter in Numerical Modelling, Peep Miidla (Ed.), InTech, 329-354 (2012) [online] http://www.intechopen.com/books/numerical-modelling/phenomenological-modellingof-cyclic-plasticity

2. Y. Jiang, J. Zhang, Benchmark experiments and characteristic cyclic plastic deformation behavior. Int. J. Plast. 24, 1481-1515 (2008)

3. R. Halama, M. Fusek, Z. Poruba, Influence of Mean Stress and Stress Amplitude on Uniaxial and Biaxial Ratcheting of ST52 Steel and Its Prediction by the AbdelKarimOhno Model. Int. J. Fatigue 91 (2), 313-321 (2016)

4. M. Handrik, P. Kopas, V. Baniari, M. Vasko, M. Saga, Analysis of stress and strain of fatigue specimens localised in the cross-sectional area of the gauge section testing on bi-axial fatigue machine loaded in the high-cycle fatigue region. Proc. Eng. 177, 516519 (2017)

5. P. Kopas, M. Saga, V. Baniari, M. Vasko, M. Handrik, A plastic strain and stress analysis of bending and torsion fatigue specimens in the low-cycle fatigue region using the finite element methods. Proc. Eng. 177, 526-531 (2017)

6. R. Halama, J. Sedlák, M. Fusek, Z. Poruba, Uniaxial and Biaxial Ratcheting of ST52 Steel under Variable Amplitude Loading - Experiments and Modeling. Proc. Eng. 101, 185-193

7. M. Krejsa, Probabilistic failure analysis of steel structures exposed to fatigue. Key Eng. Mat. 577-578, 101-104 (2014)

8. R. Halama, L. Lipinová, R. Páleník, Measurement of Cyclic Creep by Digital Image Correlation Method. In Proceedings of 55th annual conference on Experimental stress analysis 2017, Hotel Atrium, Nový Smokovec, Slovakia, May $30^{\text {th }}-$ June $1^{\text {st }}, 2017$, 300-306 (2017)

9. S. Bari, T. Hassan, Anatomy of Coupled Constitutive Models for Ratchetting Simulations, Int. J. of Plast. 16, 381-409 (2000)

10. R. Halama, M. Fusek, M. Šofer, Z. Poruba, P. Matušek, R. Fajkoš, Ratcheting Behavior of Class $C$ Wheel Steel and Its Prediction by Modified AbdelKarim-Ohno Model. In Proceedings of the $10^{\text {th }}$ International Conference on Contact Mechanics CM2015, Colorado Springs, Colorado, USA, August 30 - September 3, 2015 